\title{
NATURE OF PERIPHERAL RESISTANCE IN ARTERIAL HYPERTENSION
}

\author{
By EUGENE A. STEAD, JR., AND PAUL KUNKEL \\ (From the Thorndike Memorial Laboratory, Second and Fourth Medical Services (Harvard), \\ Boston City Hospital, and the Department of Medicine, Harvard Medical School, Boston)
}

(Received for publication July 31, 1939)

The nature of the arteriolar resistance and its distribution in the body remain the fundamental problem in the study of arterial hypertension in man. Since the cardiac output is normal in this state (1), the "average arteriolar resistance" at rest must be increased. The extent to which the peripheral resistance is increased in various tissues can be determined by comparing the blood flow in the different tissues in both normal and hypertensive subjects under similar conditions. If in arterial hypertension the peripheral resistance in any one part is not increased, the blood flow in that part will be greater than in normal subjects.

Since the cardiac output at rest is normal in arterial hypertension, the "average tissue blood flow" must also be normal. This has been confirmed by the demonstration that in hypertensive subjects the blood flow is normal in the hand and forearm $(2,3)$. While it is of interest to gather further information on the "resting" blood flow in other organs in normal and hypertensive subjects, it is of particular importance to ascertain whether the increased peripheral resistance in arterial hypertension can be lowered to a normal level in any one organ by potent vasodilating stimuli. If the increased peripheral resistance which exists at rest in arterial hypertension can be lowered to normal in any one organ, as manifested by a faster blood flow than is present in that organ in normal subjects under similar conditions, then the increased peripheral resistance at rest is the result of functional vasoconstriction, and is not the result of permanent, irreversible structural changes in the vessels. If the increased peripheral resistance present in arterial hypertension, however, cannot be reduced to normal by powerful vasodilating stimuli, as indicated by the finding of the same blood flow in the tissues of both normal and hypertensive subjects when the vessels are maximally dilated, then there are at least two obvious explanations: The chemical or other factors, which cause the vasoconstric- tion and the increased peripheral resistance, remain active in the presence of the various physiological stimuli applied and prevent the vessels from dilating as widely as normally; or the increased peripheral resistance is the result of permanent structural changes and, therefore, the vessels cannot dilate as widely as normally.

Other investigators have shown that the increased peripheral resistance, which is present in the usual types of clinical arterial hypertension, is not reflex or neurogenic in origin. Prinzmetal and Wilson (2) demonstrated that on eliminating the vasoconstrictor influences by heating the body, or by novocainization of the sympathetic ganglia, the blood flow in the forearm in subjects with arterial hypertension increased as much as, but no more than, in normal subjects. They concluded, therefore, that, as the peripheral resistance remained increased in arterial hypertension after the removal of all vasconstrictor impulses, it could not be neurogenic in origin. Recent work, however, has shown that the method used by Prinzmetal and Wilson for determining the blood flow in the forearm measured not only the arterial inflow in the forearm, but also a considerable portion of the venous blood returning from the hand $(4,5)$.

Using a calorimeter, Pickering (3) measured in both normal and hypertensive subjects the blood flow in the hand after the elimination of vasoconstrictor impulses by heating the body. This procedure produced the same increase in blood flow in both the normal and hypertensive subjects. He concluded, therefore, that the increased peripheral resistance in arterial hypertension was not neurogenic in origin. These investigators $(2,3)$ likewise observed that the increase in blood flow in the forearm after arterial occlusion was the same in normal and hypertensive subjects. Both of the above studies $(2,3)$ clearly showed that, in the usual clinical types of hypertension, the peripheral resistance in the hand and forearm was increased at rest, and that 
while the vessels were capable of dilating in response to the stimuli employed, they never dilated to as great an extent as did normal vessels under similar circumstances. It was possible, however, that the high peripheral resistance present in the skin in arterial hypertension had not been reduced to normal because the stimuli employed had not produced maximal dilatation. Observations of the blood flow in the hand and foot (6) have shown that heating the body was usually not as effective a stimulus for inducing complete vasodilatation as was the combination of local heat to the skin and heating the body, which was produced by placing the parts to be studied in a water bath at $43^{\circ} \mathrm{C}$.

The present investigation has been carried out to determine with reliable methods whether the high average arteriolar resistance, which is present throughout the body at rest in arterial hypertension, can be reduced to normal in any one tissue by the use of appropriate local vasodilating agents. The skin of the hand and foot, the muscles of the forearm, and the brain were the tissues selected for study. In order to determine to what extent permanent structural changes in the vessels entered into the production of the increased peripheral resistance in arterial hypertension, the peripheral blood flow was studied in 2 hypertensive subjects both before and after the high arterial pressure had been greatly reduced by malaria. These 2 subjects also offered a good opportunity for studying the vasomotor reflexes in the same persons at two widely different levels of arterial pressure.

\section{METHODS}

Since a given vasodilating stimulus is not uniformly effective in all parts of the body (5), different means were used for producing vasodilatation in the skin, muscle, and brain.

Vasodilatation was obtained in the hand and foot by maintaining the water baths in plethysmographs at a temperature of $43^{\circ} \mathrm{C}$. As two parts (both feet, or hand and foot) were usually studied at one time, the subjects became hot enough to sweat, and the vasodilating effect of the local heat was supplemented by the effect of heating the body as a whole. The blood flow in the hand and foot was measured by plethysmographic methods $(7,8)$ and recorded as cubic centimeters per minute per $100 \mathrm{cc}$. of tissue. As previously stated (6), when the vessels are widely dilated, the inflow curves are much more accurate in the foot than in the hand. This is the result of the slower blood flow and the relatively greater venous bed in the foot, and of the higher hydrostatic pressure in the foot plethysmograph. Each determination consisted of an average of five separate tracings, and three or more separate determinations were made at 5minute intervals until the blood flow became constant. The subjects rested on a table in the horizontal position with the water in the plethysmographs at a temperature of $43^{\circ} \mathrm{C}$. for at least 30 minutes before readings were taken. The room temperature was not carefully controlled because when the parts studied were immersed in water at $43^{\circ} \mathrm{C}$. ordinary variations in room temperature did not appreciably influence the blood flow.

The vessels of the muscles of the forearm were dilated by a combination of exercise and arterial occlusion. The blood flow in the forearm was measured in the plethysmograph described by Lewis and Grant (9), and recorded as cubic centimeters per minute per 100 cc. of tissue. A cuff distal to the plethysmograph was inflated to $300 \mathrm{~mm}$. $\mathrm{Hg}$ before the blood flow was measured in the forearm. The subjects compressed a firm rubber bulb every 5 seconds for 3 minutes. During the period of exercise blood was prevented from entering the forearm by inflating a cuff on the upper arm to $300 \mathrm{~mm}$. Hg. After the exercise had been completed the proximal occluding cuff was rapidly deflated, and the first rapid inflow of blood into the forearm was measured. It was essential to measure the first inflow of blood, because after a few seconds the veins emptying the forearm became so engorged that the application of the "collecting cuff" produced a fluid wave large enough to distort the inflow curves.

The vessels of the brain were dilated by progressively decreasing the blood flow to the brain by placing the subjects in the upright position after the oral ingestion of 0.18 gram (3 grains) of sodium nitrite (10). Syncope was induced in both normal and hypertensive subjects, and the level of the arterial pressure at which syncope occurred was recorded. The occurrence of syncope indicated that the blood flow through the brain had fallen to approximately the same level in both hypertensive and normal subjects. Therefore, the arterial pressure at that time indicated whether comparable vasodilatation had taken place in the brains of the two groups.

Two subjects with arterial hypertension and syphilis were given malaria. In both instances a marked, temporary fall in arterial pressure occurred. The blood flow in the foot at $43^{\circ} \mathrm{C}$. and the vasomotor reactions in the foot were measured before and after the fall in arterial pressure. In 1 subject the blood flow in the forearm after exercise was measured before and after the decrease in arterial pressure.

\section{RESULTS}

Subjects investigated. Sixteen patients with arterial hypertension were studied. The average age of this group was 43 years. The average systolic pressure was $206 \mathrm{~mm}$. $\mathrm{Hg}$, the highest 270 $\mathrm{mm}$. and the lowest $162 \mathrm{~mm}$; the average dias- 
tolic pressure was $131 \mathrm{~mm}$., the highest $162 \mathrm{~mm}$. and the lowest $110 \mathrm{~mm}$. Clinically, the patients were divided as follows: 3 cases of malignant hypertension following pyelonephritis, 5 cases of malignant hypertension of unknown etiology, 8 cases of essential hypertension. As all the cases did not have complete genito-urinary studies, some cases of hypertension from pyelonephritis may have been overlooked. No manifestations of failure of the heart were present at the time of examination. There were no cases of acute glomerular nephritis or, as far as could be determined, of chronic glomerular nephritis. Pulsations in all the peripheral vessels were easily palpable with the exception of 1 case of essential hypertension in whom the posterior tibial pulse in the left foot was not felt.

Blood flow in the skin. The blood flow in the foot, with the vessels dilated by local heat of $43^{\circ}$ C., averaged $21.7 \mathrm{cc}$. per minute per $100 \mathrm{cc}$. of foot in 29 feet from 16 subjects with arterial hypertension. The greatest flow was $34 \mathrm{cc}$. and the lowest $14 \mathrm{cc}$. In a previous study (6), the average blood flow in 48 feet from a group of 34 normal subjects ranging in age from 17 to 67 years was $17.1 \mathrm{cc}$. per minute per $100 \mathrm{cc}$. of foot. The average foot flow in the hypertensive group was 27 per cent faster than in the normal group. The normal subjects, however, had a wide age distribution, while 14 out of the 16 hypertensive subjects were between 30 and 50 years of age. When the values for the blood flow, therefore, are broken down into corresponding decades as in Figure 1, it is clear that the blood flow in the foot, with the vessels dilated by heat, is not significantly less in normal than in hypertensive subjects. In these patients there is no apparent correlation between the etiology of the hypertension and the blood flow in the foot. In 4 of these hypertensive subjects the average blood flow in the hand at $43^{\circ} \mathrm{C}$. was $31 \mathrm{cc}$. per minute per $100 \mathrm{cc}$. of tissue. In 18 normal subjects (6) the average hand flow at $43^{\circ} \mathrm{C}$. was $32 \mathrm{cc}$. Again the blood flow in the dilated hand is not significantly different in normal and in hypertensive subjects.

The simultaneous determination of the blood flow in the hand and foot at $43^{\circ} \mathrm{C}$. in these cases of arterial hypertension demonstrates the fallacy of drawing conclusions about the general state

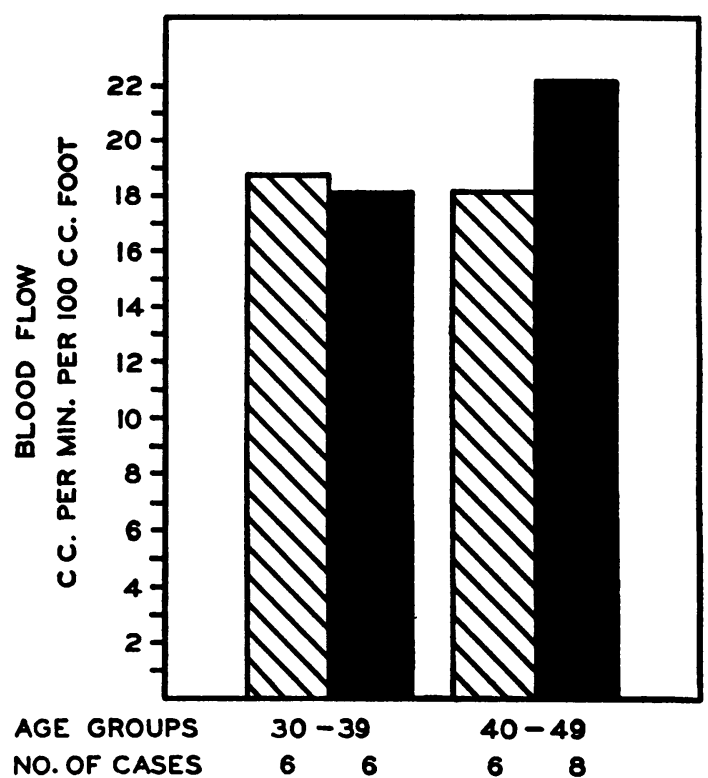

Fig. 1. The Blood Flow in the Foot at $43^{\circ}$ C. In Normal and in Hypertensive Subjects

Barred columns represent normal, solid represent hypertensive subjects. There was no significant difference in the blood flow in the foot in the two groups.

of the peripheral resistance from studies of the blood flow in one part of the body. Thus the foot flow at $43^{\circ} \mathrm{C}$. in 1 subject, E. P., averaged $34 \mathrm{cc}$. This value was very high, but the blood flow in the hand at $43^{\circ} \mathrm{C}$. and the blood flow through the brain, as estimated by the oxygen difference between arterial and internal jugular blood, were normal.

Blood flow in the muscle. The blood flow in the muscles of the forearm after a standard amount of exercise was measured in 6 normal and 3 hypertensive subjects. While the standardization of the exercise was not exact, it did not seem advisable to make it more precise, since the variations in amount of muscle in the forearm and in the general physical training of the subjects were factors beyond control. During the period of exercise blood was excluded from the forearm in order to secure maximal dilatation of the muscle vessels in as short a time as possible. The water bath surrounding the forearm was maintained at $30^{\circ} \mathrm{C}$. While the 3 -minute period of arterial occlusion undoubtedly caused some increase in blood flow in the skin, at the temperature selected vasodilatation in the skin was far from maximal and, hence, most of the rise in forearm 
flow was the result of an increase in muscle flow. The exercise, which consisted of compressing a firm rubber ball every 5 seconds for 3 minutes, was sufficient to tire the muscles of the forearm and usually caused a rise in the arterial pressure in both normal and hypertensive subjects. Thirty seconds before the end of the exercise the average arterial pressure in the normal subjects was 124 $\mathrm{mm}$. systolic and $85 \mathrm{~mm}$. diastolic. In the hypertensive subjects at a similar time the average arterial pressure was $229 \mathrm{~mm}$. systolic and $147 \mathrm{~mm}$. diastolic. In the 6 normal subjects the blood flow immediately after exercise averaged $26.5 \mathrm{cc}$. per minute per $100 \mathrm{cc}$. of forearm, with extremes of $25 \mathrm{cc}$. and $28 \mathrm{cc}$. In 3 hypertensive subjects the blood flow after exercise averaged $31.2 \mathrm{cc}$., with extremes of $30 \mathrm{cc}$. and $33 \mathrm{cc}$. The average blood flow immediately following exercise was 18 per cent faster in the hypertensive than in the normal subjects. The hypertensive subjects, however, were not in as good general physical condition as the normal subjects and, though the exercise was nearly maximal for the hypertensive subjects, it did not completely tire out the muscles of the forearm in the normal persons. The experiment was, therefore, repeated in 1 normal subject in whom the blood flow after exercise had been 25 cc. This time the exercise periods were spaced at 15-minute instead of 30-minute intervals, so that after the third trial the exercise became as nearly maximal as it had been in the hypertensive group. Under these conditions the forearm flow was $33 \mathrm{cc}$., indicating that in the previous experiments on the effect of exercise in normal subjects maximal dilatation of the vessels had not been obtained. It is, therefore, concluded that under the maximal effect of the vasodilating factors present in exercise the blood flow is essentially the same in normal subjects and in patients with arterial hypertension.

Blood flow in the brain. As calculated from the $\mathrm{O}_{2}$ differences between arterial and internal jugular blood, the blood flow through the resting brain is normal in subjects with arterial hypertension (11). These experiments do not demonstrate, however, whether the cerebral vessels can dilate to a normal degree under physiological stimuli. A progressive reduction in blood flow to the brain was selected as the best means for producing vasodilatation in the brain. It has been demonstrated experimentally that in cats cerebral " anemia" produced by clamping the carotid arteries or by a sudden, extreme fall in blood pressure caused dilatation in the vessels of the pia (12). Wolff and Lennox showed that this vasodilatation occurred as the result of an increase in carbon dioxide content of the blood, and that it could also be produced by the introduction of other acids into the blood (13). It has also been demonstrated (14) that the cerebral vessels in man dilate when the carbon dioxide content of the blood is increased or when marked anoxemia is produced.

If cerebral anoxia is induced by the oral administration of sodium nitrite in the upright position (10), the subjects should faint at approximately the same level of arterial pressure if the vessels of the brain of the hypertensive subjects are capable under such conditions of dilating to a normal degree. If, on the other hand, they cannot dilate to the same degree as do normal vessels, fainting should occur at a higher level of arterial pressure. In the 3 hypertensive subjects tested, the patients developed signs of cerebral anoxia with arterial pressure levels of 210,170 , $140 \mathrm{~mm}$. systolic and $130,100,118 \mathrm{~mm}$. diastolic, respectively. In a series of normal controls, symptoms of cerebral anoxia did not develop until the systolic pressure had fallen to around $70 \mathrm{~mm}$. $\mathrm{Hg}$. In these cases of arterial hypertension, therefore, the peripheral resistance in the brain could not be lowered to normal level by inducing cerebral anoxia.

Reduction of the arterial pressure after malaria. Two subjects with arterial hypertension were studied both before and after malaria therapy. The first case, M. F., was a 30-year-old, white female, whose arterial pressure in January, 1937, was $140 \mathrm{~mm}$. systolic and $100 \mathrm{~mm}$. diastolic. In January, 1938, the arterial blood pressure was 200 $\mathrm{mm}$. systolic and $130 \mathrm{~mm}$. diastolic. The peripheral vessels and the vessels of the fundi were normal. The heart was not enlarged. Pyelograms were negative. The clinical diagnosis was essential hypertension. The patient also had central nervous system syphilis with a paretic gold curve. She was given two courses of malarial therapy, the first in 1938, and the second in 1939, and each time the arterial pressure became much lower, both during and for some time after the 


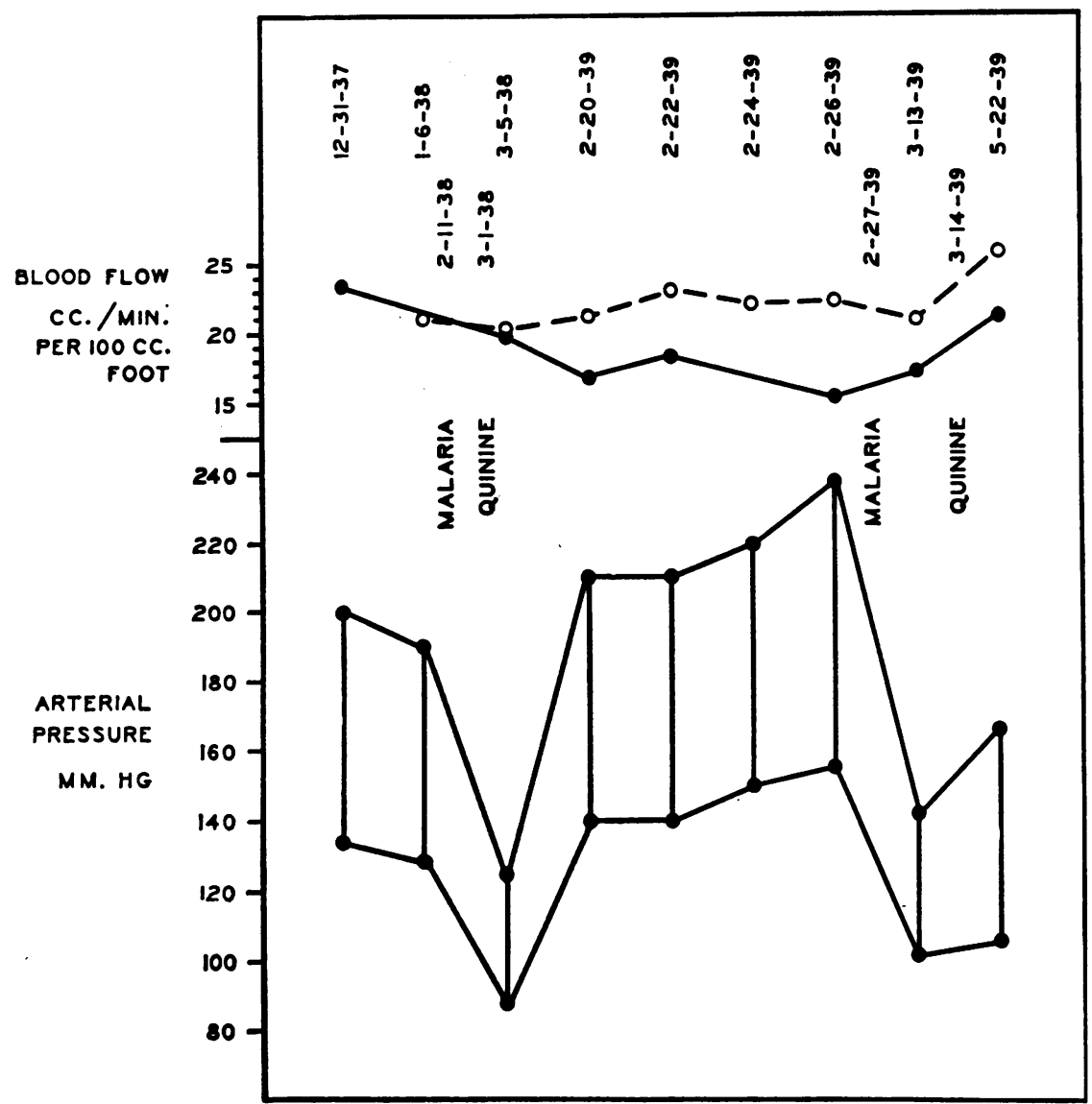

Fig. 2. The Blood Flow in the Foot at $43^{\circ}$ C. in Patient M. F.

The arterial pressure on two occasions was decreased during, and for some time after, a course of malaria. The blood flow in the foot did not decrease as the arterial pressure fell. Solid line $=$ right foot, broken line $=$ left foot.

course of malaria. The blood flow in the foot showed no significant change when the arterial pressure fell (Figure 2).

In the same patient on two occasions the blood flow in the forearm after exercise was $33 \mathrm{cc}$. and $32 \mathrm{cc}$. respectively, when the arterial pressure was $240 \mathrm{~mm}$. systolic and $150 \mathrm{~mm}$. diastolic. After the second course of malaria the blood flow in the forearm after exercise was $35 \mathrm{cc}$. when the arterial pressure was $150 \mathrm{~mm}$. systolic and 110 $\mathrm{mm}$. diastolic.

The second patient was a 44-year-old colored woman who had hypertension for at least $41 / 2$ years before her entry into the hospital in December, 1938. The vessels of the fundi showed marked narrowing. The peripheral vessels were diffusely thickened and the left posterior tibial pulse was not palpable. The heart was moder- ately enlarged. The Wassermann was positive. The clinical diagnosis was essential hypertension and latent syphilis. The arterial pressure was decreased during, and for some time after, the course of malaria. The blood flow in the foot at $43^{\circ} \mathrm{C}$. decreased when the arterial pressure fell (Figure 3).

In both cases malaria caused a marked reduction in the arterial pressure at rest. In the first case, the increased peripheral resistance had not resulted in any structural changes in the vessels. In the second case, however, permanent structural changes had occurred.

Vasomotor reactions in arterial hypertension. In subjects with arterial hypertension, sensory stimuli such as noise, pinch, or deep breath, produced vasoconstriction in the hand and foot. These reactions were qualitatively and quantita- 


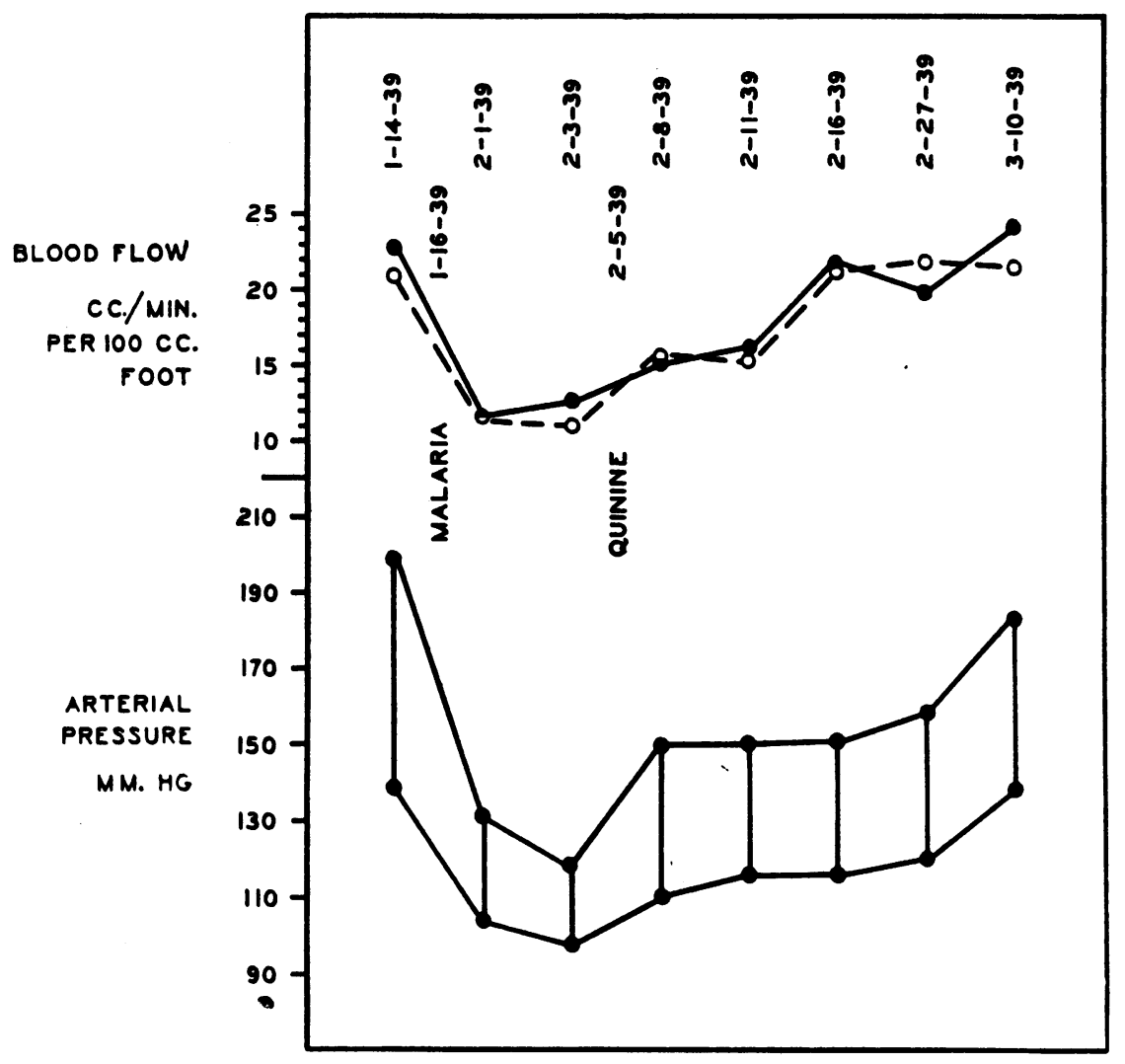

Fig. 3. The Blood Flow in the Foot at $43^{\circ}$ C. in Patient D. M.

The arterial pressure was decreased during, and for some time after, a course of malaria. The blood flow in the foot became slower when the arterial pressure decreased. Solid line $=$ right foot, broken line $=$ left foot.

tively similar to those occurring in normal subjects. Vasoconstrictor responses were also obtained in 2 subjects both before and after the arterial pressure was lowered by a course of malaria. There was no difference in the vasomotor responses in the same subject at the two widely different levels of arterial pressure (Figure 4).

\section{DISCUSSION}

These experiments demonstrate that the average peripheral resistance in arterial hypertension is increased fairly uniformly in the skin, the muscles, and the brain, and that it cannot be lowered to normal levels by strong, physiological dilating agents. Studies of renal function in arterial hypertension (15) have shown that the peripheral resistance is also increased in the kidney because the blood flow in the kidney, as determined by the urea or creatinine clearance tests, is no faster in hypertensive than in normal subjects. The measurement of the blood flow and the peripheral resistance in the splanchnic area in man is not practicable as yet. However, since in arterial hypertension the peripheral resistance is increased in the skin, muscle, brain and kidneys, and since the cardiac output is normal, one can assume that the blood flow in the splanchnic area is the same as in normal subjects; and that, therefore, the peripheral resistance in the splanchnic area is not raised to a greater degree than in the other tissues.

The finding of a uniform increase in peripheral resistance in the skin, brain and muscle is strong evidence against the neurogenic vasomotor origin of the usual clinical types of arterial hypertension. The amount of vasomotor activity varies greatly in these three tissues. Vasoconstrictor impulses play a large part in the regulation of the blood flow in the skin of the hand and foot; they play 
a minor part in the regulation of the blood flow in the brain and, as far as is known, they play no part in regulation of blood flow in the muscle. Therefore, it is very unlikely that any abnormality of the vasomotor system, or any increase in sensitivity of the vasomotor system, would produce the same relative increase in the peripheral resistance in these three tissues which normally show such a great difference in vasomotor activity. formed which counteracted the effect of a vasoconstrictor substance or influence; or because a vasoconstrictor substance was no longer formed, was neutralized, or excreted.

Although the behavior of the peripheral circulation at rest appeared to be identical in these 2 subjects, the response of the vessels to vigorous dilating stimuli was different. In the case of M. F., the blood flow in the foot at $43^{\circ} \mathrm{C}$., and

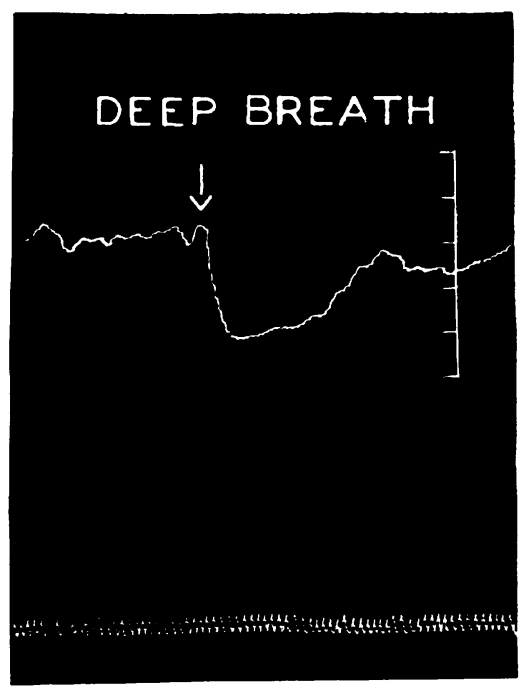

A

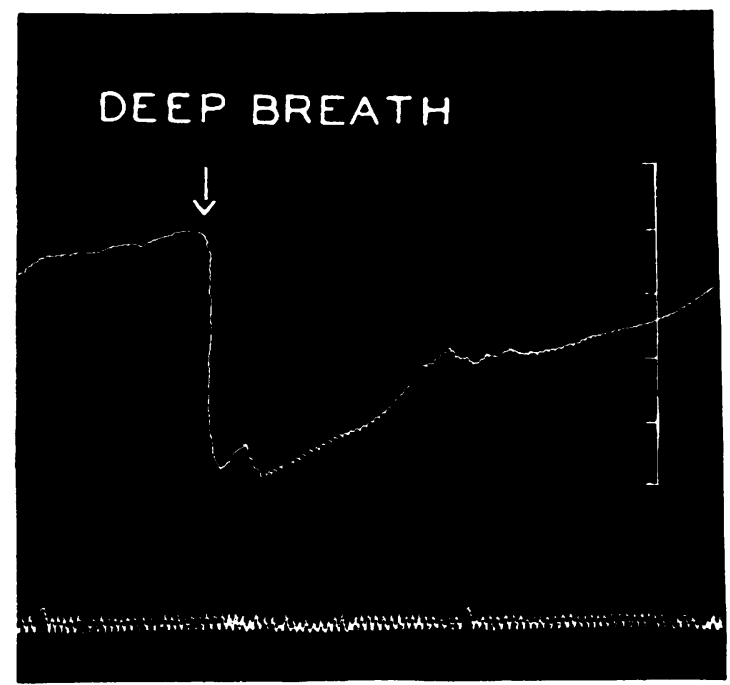

B

Fig. 4. Vasoconstrictor Response in Left foot of Patient D. M., Induced by a Deep INSPIRATION

The vasomotor responses to sensory stimuli did not change when the arterial pressure fell. Note that the calibration of the recording bellows differs in $\mathrm{A}$ and $\mathrm{B}$.

A. Before malaria-arterial pressure was $200 \mathrm{~mm}$. systolic and $140 \mathrm{~mm}$. diastolic.

B. After malaria-arterial pressure was $120 \mathrm{~mm}$. systolic and $98 \mathrm{~mm}$. diastolic.

These experiments on the blood flow in the skin, muscle and brain do not demonstrate whether the increased peripheral resistance in hypertension results from a humoral vasoconstrictor substance, or from permanent structural changes in the vessels. The subjects who were given malaria throw some light on this problem.

In the 2 patients who were given malaria, sufficient vasodilatation occurred at rest to produce a marked decrease in arterial pressure. The blood flow at rest was adequate as shown by warm extremities, full pulse and adequate output of urine. No information was obtained, however, as to whether this vasodilatation took place because a powerful vasodilator substance was in the muscles of the forearm after exercise, did not decrease with the fall in arterial pressure because permanent structural changes in the vessels had not taken place. Therefore, when the hypothetical vasoconstrictor substance, which had caused the increased peripheral resistance and the hypertension, was no longer active, the vessels were able to dilate more fully in response to various physiological stimuli and to maintain the same blood flow with a lower pressure head. In the second subject, D. M., the blood flow in the foot at $43^{\circ} \mathrm{C}$. decreased when the arterial pressure fell because there were permanent structural changes in the vessels. Therefore, even when the hypothetical vasoconstrictor substance originally 
causing the increase in peripheral resistance was not active, the vessels were not able to dilate suffic.ently in response to heat to compensate for the fall in arterial pressure.

In both of these cases, however, the arterial hypertension resulted from active vasoconstriction, presumably humoral in origin rather than from structural changes in the vessels because, even in the second case which had developed permanent vascular damage, sufficient vasodilatation occurred to reduce the arterial pressure when the reversible factors causing the original high arterial pressure were not active.

The vasomotor responses in the hand and foot to sensory stimuli were similar both qualitatively and quantitatively in normal and in hypertensive subjects. In the 2 hypertensive subjects who showed a marked fall in arterial pressure sensory stimuli produced vigorous vasoconstriction regardless of the height of the arterial pressure. These observations are in accord with the findings of other observers $(2,3)$.

\section{SUMMARY AND CONCLUSIONS}

1. The increased peripheral resistance present in arterial hypertension cannot be reduced to the normal level in the skin of the hand and the foot, the muscles of the forearm, or in the brain by powerful vasodilating stimuli.

2. The blood flow in the hand and foot at $43^{\circ}$ C. and in the muscles of the forearm after exercise shows no significant difference in normal and in hypertensive subjects.

3. In hypertensive subjects cerebral anoxia does not reduce the peripheral resistance in the vessels of the brain to normal levels. Therefore, in postural experiments after the administration of sodium nitrite, subjects with arterial hypertension develop syncope with a much higher arterial pressure than do normal subjects.

4. The finding of a uniform degree of elevation of the peripheral resistance throughout the body is strong evidence against the neurogenic origin of the usual types of clinical hypertension because the nervous vasomotor control is different in each of the tissues investigated.

5. In 1 subject with arterial hypertension, a marked fall in arterial pressure after malaria produced no change in the blood flow in the foot at $43^{\circ} \mathrm{C}$., indicating that no structural changes had taken place in the vessels. In a second subject the blood flow in the foot at $43^{\circ} \mathrm{C}$. was decreased when the arterial pressure fell, indicating that permanent vascular damage had occurred. The arterial hypertension in both of these subjects originally resulted from active vasoconstriction. In 1 , structural changes had later developed.

6. Sensory stimuli, such as pinch, noise, and deep breath, produce vasoconstriction of similar degree in both normal and hypertensive subjects. When the arterial pressure is greatly lowered following malaria, these vasoconstrictor responses remain unchanged.

7. In arterial hypertension the peripheral resistance is uniformly raised throughout the area of the greater circulation, and it is not increased in the splanchnic area to any greater extent than in other tissues.

The authors wish to express their appreciation to Dr. Soma Weiss for helpful guidance and criticism in this work. This investigation was carried out with the technical assistance of Miss Sophia M. Simmons, S. B.

\section{BIBLIOGRAPHY}

1. Weiss, S., and Ellis, L. B., Quantitative aspects and dynamics of circulatory mechanism in arterial hypertension. Am. Heart J., 1930, 5, 448.

2. Prinzmetal, M., and Wilson, C., Nature of peripheral resistance in arterial hypertension with special reference to vasomotor system. J. Clin. Invest., 1936, 15, 63.

3. Pickering, G. W., Peripheral resistance in persistent arterial hypertension. Clin. Sc., 1936, 2, 209.

4. Grant, R. T., and Pearson, R. S. B., Blood circulation in human limb; observations on differences between proximal and distal parts and remarks on regulation of body temperature. Clin. Sc., 1938, 3, 119.

5. Kunkel, P., Stead, E. A., Jr., and Weiss, S., Blood flow and vasomotor reactions in hand, forearm, foot, and calf in response to physical and chemical stimuli. J. Clin. Invest., 1939, 18, 225.

6. Kunkel, P., and Stead, E. A., Jr., Blood flow and vasomotor reactions in foot in health, in arteriosclerosis, and in thromboangiitis obliterans. J. Clin. Invest., 1938, 17, 715.

7. Freeman, N. E., Effect of temperature on rate of blood flow in normal and in sympathectomized hand. Am. J. Physiol., 1935, 113, 384.

8. Stead, E. A., Jr., and Kunkel, P., Plethysmographic method for quantitative measurement of blood flow in foot. J. Clin. Invest., 1938, 17, 711. 
9. Lewis, T., and Grant, R., Reactive hyperaemia in man. Heart, 1925, 12, 73.

10. Weiss, S., Wilkins, R. W., and Haynes, F. W., Nature of circulatory collapse induced by sodium nitrite. J. Clin. Invest., 1937, 16, 73.

11. Weiss, S., Unpublished observations.

12. Forbes, H. S., and Wolff, H. G., Cerebral circulation. III. Vasomotor control of cerebral vessels. Arch. Neurol. and Psychiat., 1928, 19, 1057.
13. Wolff, H. G., and Lennox, W. G., Cerebral circulation. XII. Effect on pial vessels of variations in oxygen and carbon dioxide content of blood. Arch. Neurol. and Psychiat., 1930, 23; 1097.

14. Lennox, W. G., and Gibbs, E. L., Blood flow in brain and leg of man and changes induced by alteration of blood gases. J. Clin. Invest., 1932, 11, 1155.

15. Ellis, L. B., and Weiss, S., Renal function in arterial hypertension. J. A. M. A., 1933, 100, 875. 